\title{
Research on Participatory Design Method of Mixed Bean Planting Machinery
}

\author{
ZHAO aili ${ }^{1}$, GUO zhanbin ${ }^{1}$, WANG liming ${ }^{1 *}$,QU qingfeng ${ }^{1}$, QIN haibin ${ }^{1}$ \\ ${ }^{1}$ Heilongjiang Bayi Agricultural University DaQing 163000
}

\begin{abstract}
To promote the realization of collaborative design path of mixed bean planting machinery by studying the application of participatory design method in mixed bean planting machinery. To clarify the importance of industrial design for the innovation and development of mixed bean planting machinery, use participatory design methods to coordinate the development trend of industrial design and mixed bean planting machinery, and guide design practice to achieve joint research and joint design, thus realizing the innovative development of mixed bean planting machinery.
\end{abstract}

\section{Introduction}

Planting is the most important part in agricultural production. At present, the mixed bean planting machinery in China mainly includes mechanical and pneumatic planters, which are relatively mature in design, but still have a lot of room for research and development in their appearance design. Therefore, this paper aims to apply the participatory design method to the mixed bean planting machinery to promote the innovative realization of its appearance design, so as to achieve the effective expression of the new technology in appearance and design.

\section{Concept and trend of participatory design}

The individual's participation makes the individual environment change. We call this kind of behavior that strongly emphasizes the individual's intention as participatory design, and its result completely depends on the participants. ${ }^{[1]}$ Participatory design stimulates the formation of a new method and thinking framework by gathering cross-domain knowledge and relevant information into a unified knowledge base, enabling it to apply or promote other cross-domain collaborations, and guide and achieve the results with high additional value.

On the one hand, participatory design can realize the effective integration and cross-domain of industrial design and mixed bean planting machinery; on the other hand, its architecture can effectively establish design thinking and manufacturing procedures, enabling industrial design to play an active role in multi-dimensional spaces such as process technology, material application, and function development. Moreover, it can empower the mixed bean planting machinery with innovative development, break the boundaries between designers, engineers and users, and solve problems and achieve innovation through the guidance of practical problems based on putting them in the position of stakeholders. In addition, the formation of the participatory framework and mode can avoid the occurrence of phenomenon such as over-compliance with market orientation, ignorance of technology, materials, structure, user psychology and needs, and obsession with subject expression that may occur in the process of integrating industrial design methods, thus creating a balanced and stable ecological environment for its joint research and joint design.

\section{Dimensions and analysis of participatory design}

The general framework of participatory design contains three dimensions: depth, breadth and scope. ${ }^{[2]}$ These three dimensions have different influences and related factors, and the connotations and trends presented in this process.

\subsection{The analysis of the "breadth" of participation}

Breadth refers to the diversity of stakeholders (such as decision makers or users) invited to participate in the process. ${ }^{[3]}$ The innovative design of mixed bean planting machinery includes the following related parties: engineer (A), industrial designer (I), user (U) and other related parties (government $(\mathrm{G})$, association (S), interdisciplinary cooperator ( C), distributor (D), etc.). In-depth and direct communication between related parties from the same perspective can make up for the

*Corresponding author's e-mail: 573053416@qq.com 
shortcomings of the single thinking mode in the past, and meet the needs of all levels in terms of design expression, market competition, and user needs.

The engineer (A) needs to make full use of personal experience and technology in the research and development process, and materialize the use environment and use situation of the mixed bean planter based on rationality and practice, and finally implement the science and technology into the product to achieve realization. The industrial designer (I) can fully understand the bean planter and its structural characteristics and process characteristics during the design process of the planter, integrate and recreate the "aesthetic" value and the "practical" value of the bean planter on the premise of adequate design research and method implementation, thus breaking through the boundaries of processing technology and expression. Users are not involved in the process of design symbolically, but have real contribution. ${ }^{[4]}$ Introducing users (U) to directly participate in the communication can fully obtain their behavior and psychological data. During the designing and developing process, it is necessary to expand from the use function of agricultural machinery to the direction of man-machine aesthetics, and then to increase the number of possible users, the scope of related parties will also be expanded accordingly. Therefore, in addition to existing users, the definition of users should also focus on the potential and new user groups of innovative categories.

Other related parties, such as government, association, interdisciplinary partner, and distributor also play an important role in the innovation process of mixed bean machinery, which can increase the chance of successful innovation of mixed bean machinery through advantages such as policy guidance and economic support. The integration and reconstruction of these multiple related factors can improve the efficiency of design information communication and realize the optimization of the innovative design process of mixed bean machinery.

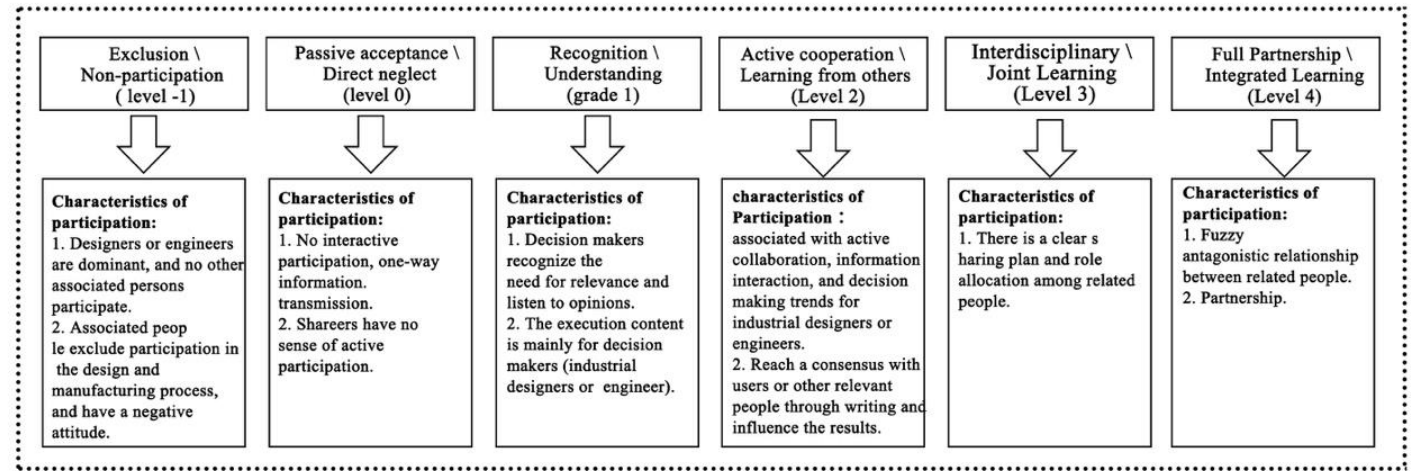

Fig 1. Participate in "depth" analysis

\subsection{The analysis of the "depth" of participation}

Depth is used in various papers to refer to the degree to which stakeholders control decisions. ${ }^{[5]}$ Different depths of participation indicate the attitudes, methods, assumptions, behaviors, or decision-making processes of related parties, and the mutual influence between them, forming a certain "power" relationship ${ }^{[3]}$, which can show the different impacts of different degree of participation of related parties on product results. Based on the innovation process, we divide the participation of the main related parties (industrial designers, engineers, users) into five levels: -1 to 4 . Level -1 refers to the lowest level of participation (rejection / nonparticipation), indicating that the views of designers or engineers are dominant, and almost no other related parties participate in it, or other related parties reject participation in the design and manufacturing process and have a negative attitude. Level 0 (passive reception / direct ignorance) refers to no interactive participation, but passive one-way information transmission; the decision maker contact with other related parties by means of notification, or related parties do not take the initiative to provide feedback on the links and contents. Level 1 (recognition / understanding) indicates that in the manufacturing process of the mixed bean planter, the decision-maker can recognize the necessity of obtaining opinions from other related parties, invite related parties to participate in creative development, processing and production, and listen to their opinions and suggestions; but the final execution content is still based on the decision of the decision maker (industrial designer or engineer), and the opinions of others are unlikely to have a significant impact on the decision. Level 2 (active cooperation / learning from others) indicates that related parties can actively cooperate and carry out effective information interaction; industrial designers or engineers still dominate the decision making trend, but they will reach a certain consensus with users or other related parties in a collaborative way, and provide stimulative appeasement or compromise for each other to the problems that may occur in the manufacturing process; the decisions of other users or related parties will affect the final result. Level 3 (interdisciplinary / co-learning) indicates that the related parties will have a clear plan and role assignment in the processing and manufacturing process, and can carry out meaningful information exchange and interaction in this process, thus achieving relatively high-quality design for mixed bean planter. Level 4 
(comprehensive partnership / integrated learning) is the highest level of participation, indicating that the cooperating related parties can blur the opposite relationship between them and consciously share knowledge and skills in order to achieve a common goal; it represents partnership, and all decisions are made by consensus $^{[3]}$.

\subsection{The analysis of the "scope" of participation}

Scope refers to all phases of an important decision. ${ }^{[5]}$ The scope of participation in the innovative design process of the mixed bean planter involves the product research phase, design phase, production phase, evaluation phase and promotion phase. As shown in Figure 2. The scope of participation has expansibility, which will be expanded gradually with the deepening of design and manufacturing, and requires mobilizing relevant factors of all parties. Based on the different types of functions and functional attributes, each phase of participation has a corresponding model structure and will be adjusted according to actual conditions. It is worth emphasizing that in this mode of participatory collaborative innovation, related parties can start from any point of demand, without the need for full participation. This change is determined by factors such as the innovation trend of the planter and its functional attributes, so the scope of participation has a certain degree of uncertainty and broadness.

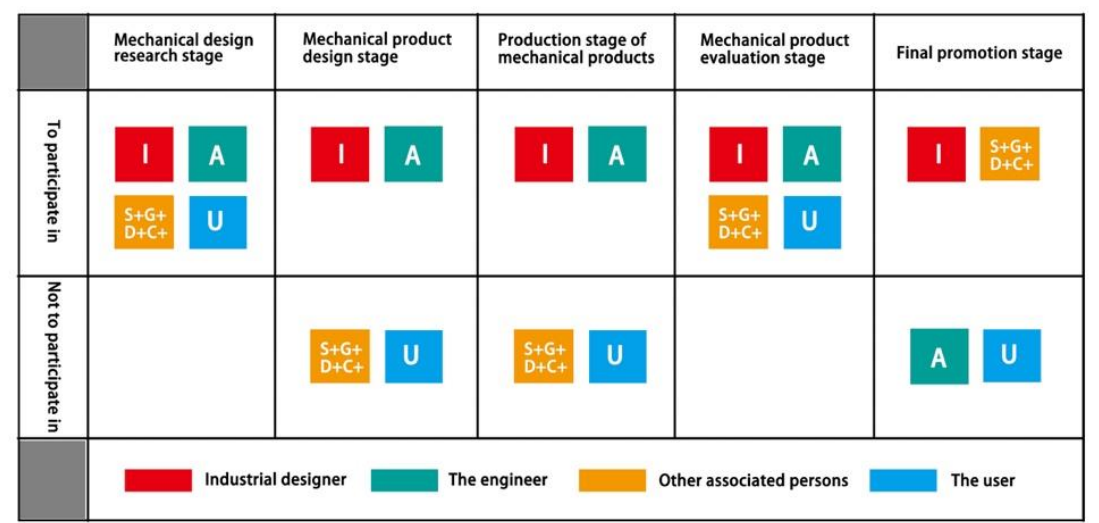

Fig 2. Participate in the "scope" analysis of the design

Number:102/2042070008)

\section{Conclusion}

This participatory design framework not only effectively promotes the cross-domain integration of industrial design and mixed bean planting machinery design, but also cooperates with other resources to jointly promote the innovative design and development of mixed bean planting machinery. The scientific and orderly design and development method of innovative product provide a clear and beneficial practice path for the innovation and remanufacturing of mixed bean planting machinery. The interworking and interfused collaboration method not only enables the effective allocation of resources in the design and manufacture of the mixed bean planting machinery, but also creates an agricultural machinery market and industry of ecological sustainable development.

\section{Acknowledgment}

Fund Project: Characteristic discipline project of " coarse cereals production and processing"(Project

\section{References:}

1. Jiang Ying, Hu Jin. Discussion on participatory Design [J]. Beijing: Decoration.2002.17-18.

2. Marie K.Harder,Gemma Burford,Elona Hoover. Whatis Participation Desgn Leads the Way to a Cross-Disciplinary Framework $[J]$.Design Issues.2013 (29): 4

3. J.Bradley Cousin,John J.Donohue, et al.Collaborative Evaluation in North America:Evaluators'Self-Reportd Opinions,practices and Consequences[J].Evaluation Practice 1996(17):207-226.

4. Tan Zhengyu, LIU Lei, JIANG Chenyang. Research on behavioral Style based on perceived Conflict in Interaction Design $[\mathrm{J}]$. Chongqing: Packaging Engineering.2019 (40) : 165-172.

5. Daigneault,Jacob.Toward Accurate Measurement of Participation [M].342,338. 